\title{
Study on Surface Heat Budget of Various Pavements for Urban Heat Island Mitigation
}

\author{
Hideki Takebayashi ${ }^{1}$ and Masakazu Moriyama ${ }^{2}$ \\ ${ }^{1}$ Department of Architecture, Graduate School of Engineering, Kobe University, kobe 657-8501, Japan \\ ${ }^{2}$ Department of Living and Environmental Design, Faculty of Science and Engineering, Setsunan University, Japan
}

Correspondence should be addressed to Hideki Takebayashi, thideki@kobe-u.ac.jp

Received 16 January 2012; Revised 16 March 2012; Accepted 16 March 2012

Academic Editor: Giovanni Polacco

Copyright (C) 2012 H. Takebayashi and M. Moriyama. This is an open access article distributed under the Creative Commons Attribution License, which permits unrestricted use, distribution, and reproduction in any medium, provided the original work is properly cited.

\begin{abstract}
The surface heat budgets of various pavement surfaces are studied with the aim of mitigating the urban heat island effect. In this study, the thermal characteristics of pavements are examined using data from observations. The net radiation, surface temperature, temperature under the surface, conduction heat flux, and core weight for each experimental surface are recorded, together with the weather conditions at the time of observation. The latent heat flux is estimated from the observed weight of the cores. The surface heat budget under the same weather conditions is examined, and the sensible heat flux from each target surface is calculated. The parameters that influence the surface heat budget, for example, solar reflectance (albedo), evaporative efficiency, heat conductivity, and heat capacity, are examined. On a typical summer day, the maximum reduction in the sensible heat flux from that on a normal asphalt surface is about $150 \mathrm{~W} / \mathrm{m}^{2}$ for an asphalt surface with water-retaining material and about $100 \mathrm{~W} / \mathrm{m}^{2}$ for a cement concrete surface with water-retaining material, depending on the albedo of each surface.
\end{abstract}

\section{Introduction}

The purpose of this study is to investigate the urban heat island mitigation effect achieved by conversion from an asphalt pavement surface to another pavement surface for ground surface improvement, which is an established urban heat island mitigation technique. Various kinds of pavements were constructed experimentally for the purpose of investigating their effect on urban heat island mitigation by analyzing the surface heat budget. The urban heat island mitigation effect is discussed from the viewpoint of the sensible heat flux reduction for each pavement.

Urban heat island mitigation technologies focus on the improvement of urban surface materials on roads, roofs, and walls. For example, roads and roofs coated with highreflectance paint are called cool roofs and cool pavements by Akbari et al. [1]. According to their estimates, the annual balances in the saving in cooling cost and the increase in heating cost obtained by introducing cool roofs are $\$ 35$ million in Los Angeles, \$16 million in New York, and \$10 million in Chicago. However, fewer studies have been carried out on roads as compared to those on green roofs [2-7], green parks [8-12], and green plantings [13-15].

In Japan, several studies have been carried out to evaluate the performance of pavements designed to have a beneficial environmental impact [16-20]. However, those studies have evaluated each technology separately and discussed only the reduction in surface temperature as compared with that in the case of a normal pavement. They have not compared the surface heat budget for each pavement. In this study, the surface heat budget for each pavement surface is examined under the same weather conditions; further, the sensible heat flux for each pavement surface is evaluated, and the urban heat island mitigation effect of that pavement is discussed.

\section{Observation Method}

The observation site is located in Taisho Ward, Osaka, Japan. Sixteen experimental surfaces are constructed. The dimensions of each surface are $2 \mathrm{~m} \times 2 \mathrm{~m}$. A plan, a photo, and different cross-sections of the observation site are given 
in Figures 1, 2, and 3, respectively, and an outline of the site is described in Table 1. In these figures, $\mathrm{A}$ refers to asphalt, B to interlocking block; and C to cement concrete. The south side of the observation site is open, and low-rise plant facilities are located on the north, west, and east sides. The distance from the observation site to the plant facilities on those three sides is about $20 \mathrm{~m}$. Asphalts, cement concretes, and interlocking blocks are included in the surfaces studied. They are classified as "normal," "porous," and "with water-retaining material." Each surface is referred to as As-N (asphalt-normal), As-P (asphalt-porous), As-W (asphalt-water retaining), Con- $\mathrm{N}$ (concrete-normal), Con-P (concrete-porous), Con-W (concrete-water retaining), Ilb-P (interlocking block-porous), and Ilb-W (interlocking blockwater retaining). Grass and bare soil provide reference sites. These surfaces are fairly representative of the various kinds of pavement technologies proposed in Japan.

An outline of observation instrument is shown in Table 2. The quantities observed are the surface and inner temperatures and conduction heat flux of each pavement and the weather conditions such as air temperature, relative humidity, global solar radiation, infrared radiation, precipitation, and wind direction and velocity. T-type thermocouples are placed at the boundaries of the pavement layers, and a conduction heat sensor is located $10 \mathrm{~mm}$ below the surface. These sensors were installed during pavement construction. The surface temperature is observed by an infrared thermometer set on the center of each surface. Weather conditions are observed near the observation site. The solar reflectance and weights of the test core, box, and block for each pavement surface, the net radiation for several pavement surfaces, and the surface temperature distribution of the observation site are observed for specific periods. The solar reflectance and net radiation are observed by a net radiation meter. The surface temperature distribution is observed by an infrared thermal camera. It was confirmed that data around the center of each surface is representative of each target, based on the observation results of the surface temperature distribution.

\section{Observations}

Observations were carried out in the summers of 2004 and 2005. In this study, the observed values from August 3 to 5, 2005, are analyzed to provide the surface heat budget for each pavement surface. The weights of the test core, box, and block are recorded during this period. The weather conditions during the observation period are shown in Figure 4. It was mostly sunny during this period, but precipitation was observed at around 15:00 LST on August 5. The sudden drop in global solar radiation at around 12:00 on August 3 was due to cloud.

3.1. Surface Temperature. The surface temperature is recorded by an infrared thermometer (Exergen, IRt/c.1X) and T-type thermocouple. The infrared thermometer is set on the north side of the target area at a height of $15 \mathrm{~cm}$ and at

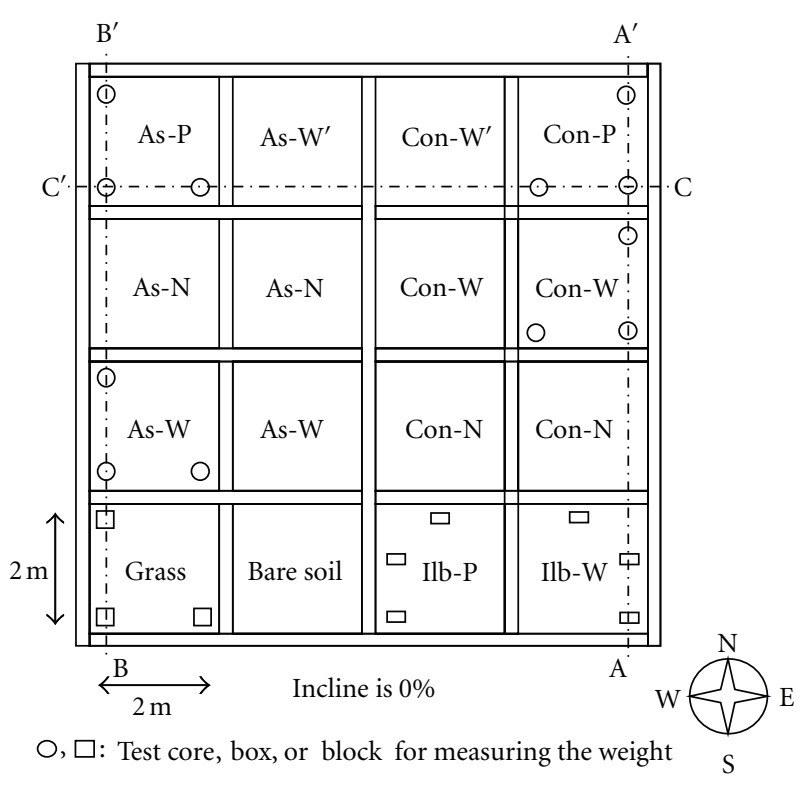

FIgURE 1: Plan of observation site.

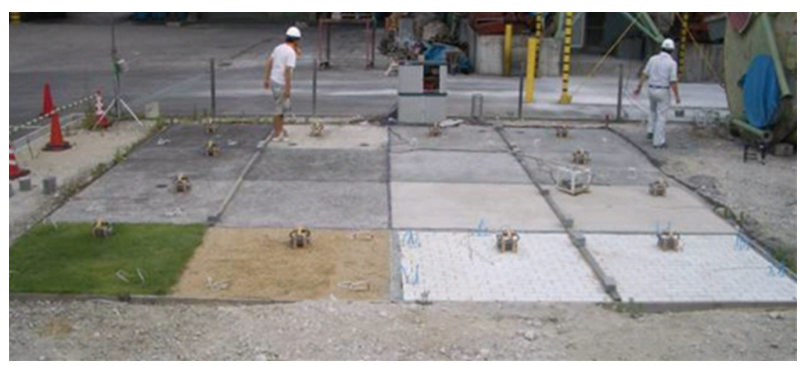

FIgURE 2: Photo of observation site (position as shown in Figure 1).

$30^{\circ}$ from the horizontal surface. The target area is an ellipse with a long-axis radius of about $24 \mathrm{~cm}$ and a short-axis radius of about $9 \mathrm{~cm}$. The T-type thermocouple is fastened to the surface by tape. The emissivity of each pavement surface in the nighttime is calculated using the values recorded by the infrared thermometer and T-type thermocouple. It was calculated using the following equation: $\varepsilon=L / \sigma T_{s}^{4}$. The emissivity of each surface ranges from around 0.97 to 1.0. In the daytime, the values recorded by the infrared thermometer are lower than those recorded by the thermocouple. The thermocouple may be directly affected by solar radiation, but the infrared thermometer is not, as it is installed only in low-temperature areas included in the targeted ellipse. The amount of solar radiation differs depending on the distribution of the aggregate, especially on porous material surfaces. The infrared sensor can capture the average surface temperature. The observed values of the surface temperature for each pavement surface are shown in Figure 5. The surface temperature for As- $\mathrm{N}$ is the highest and that for grass is the lowest. The maximum difference in the daytime temperature between As- $\mathrm{N}$ and grass is about $20^{\circ} \mathrm{C}$ and that in the nighttime is less than about $4^{\circ}$. 
TABLE 1: Outline of observation site.

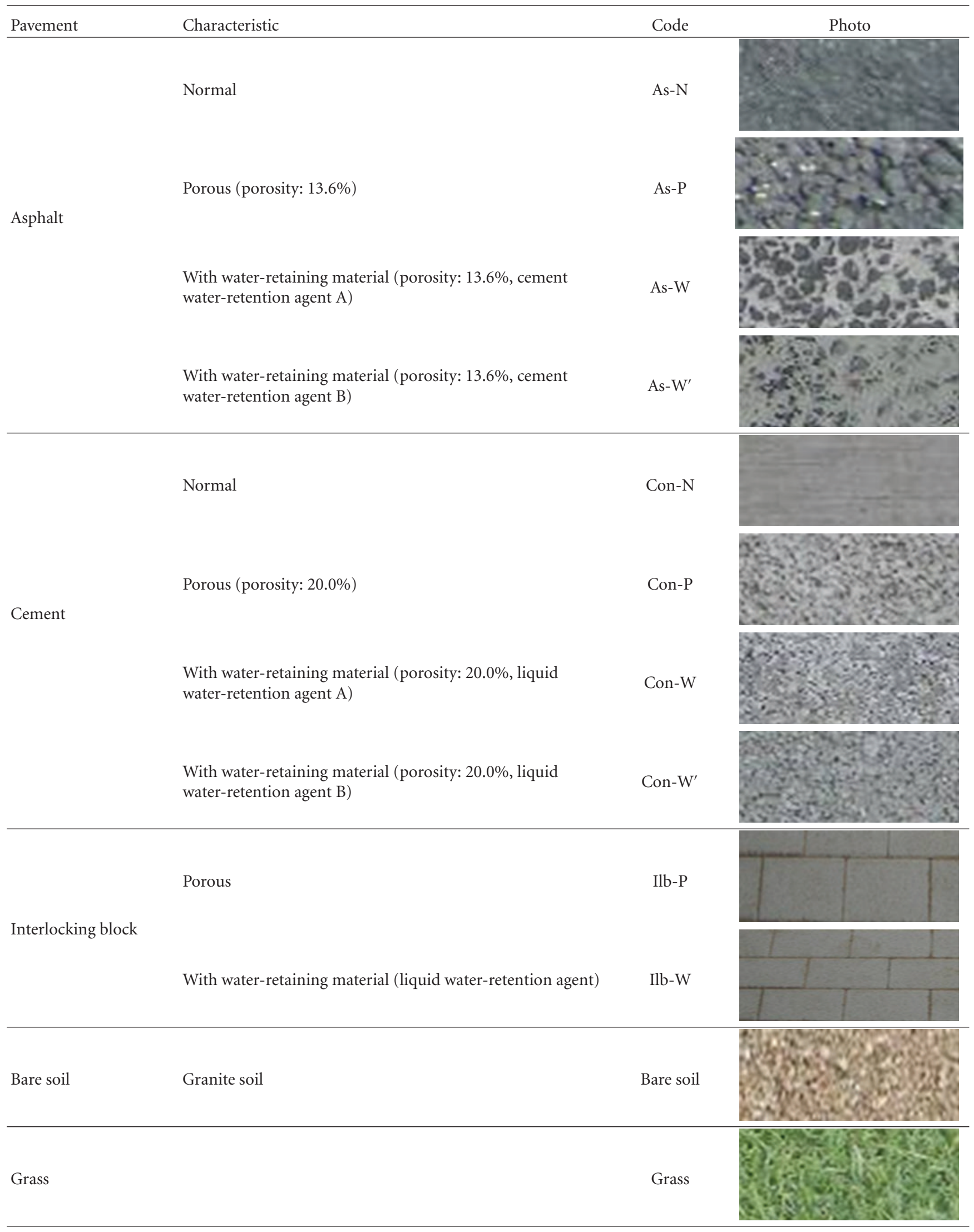




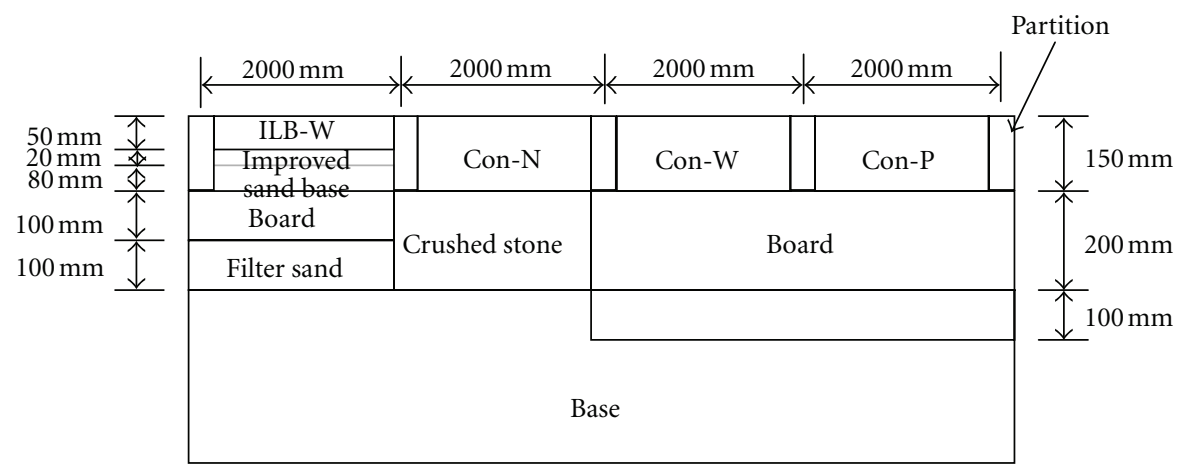

(a) A-A' section

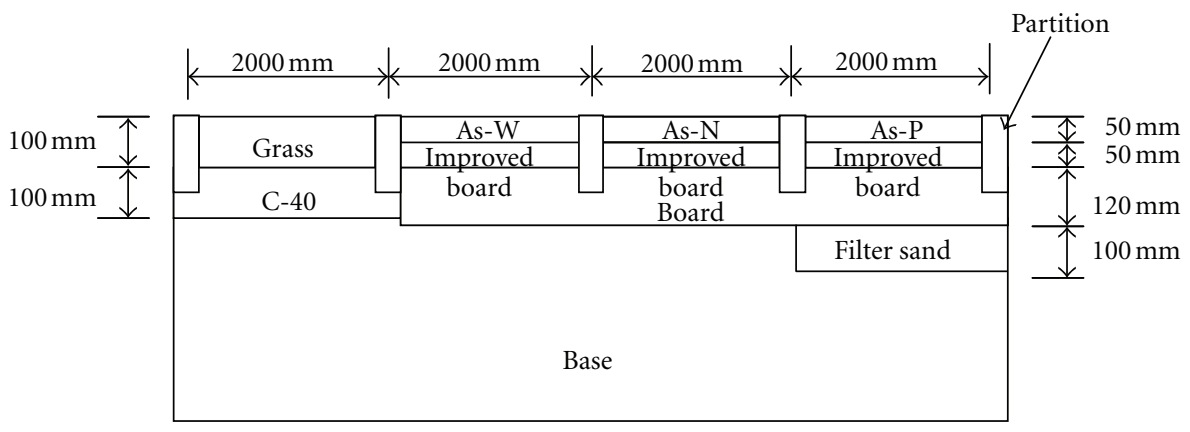

(b) B-B' section

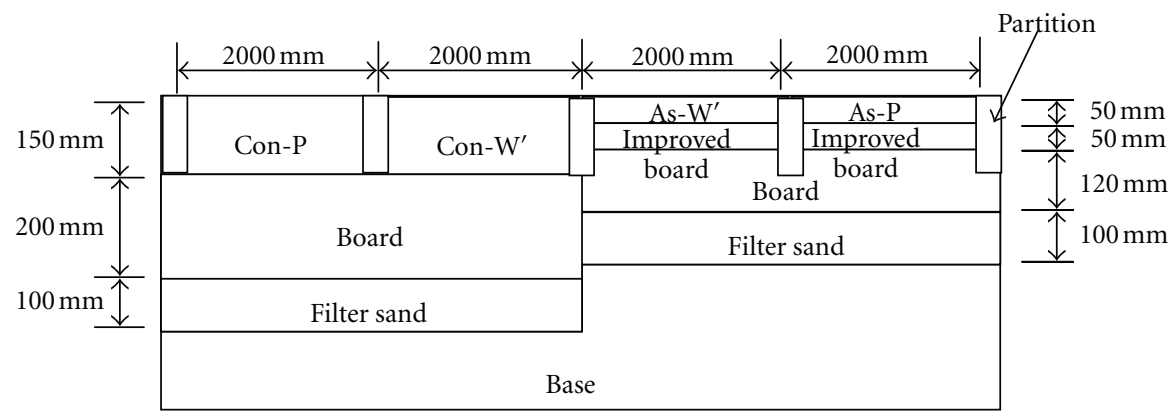

(c) C-C' section

FiguRE 3: Cross-sections of observation site.

TABLE 2: Outline of observation instrument.

\begin{tabular}{lc}
\hline Element & Instrument and accuracy \\
\hline Global solar radiation and infrared radiation & Eko, MR-50, $6 \%$ \\
Wind direction and velocity & Prede, O34S, $0.1 \mathrm{~m} / \mathrm{s}$ (WS), $\%$ (WD) \\
Air temperature and relative humidity & Espec, RS-12, $\pm 0.3^{\circ} \mathrm{C}, \pm 5 \%$ \\
Precipitation & Eko, NW-010, $0.5 \mathrm{~mm}$ \\
Surface temperature & Exergen, IRt/c.1X, $\pm 2 \%$ \\
Surface and inner temperature & T-type thermocouple \\
Heat flow & Eko, MF-180M \\
Weight & Weighting \\
Downward/upward and short-wave/long-wave radiation & Kipp \& Zonen, CPR-CNR1, $\pm 10 \%$ \\
Surface temperature distribution & Avio, TVS-600 \\
\hline
\end{tabular}




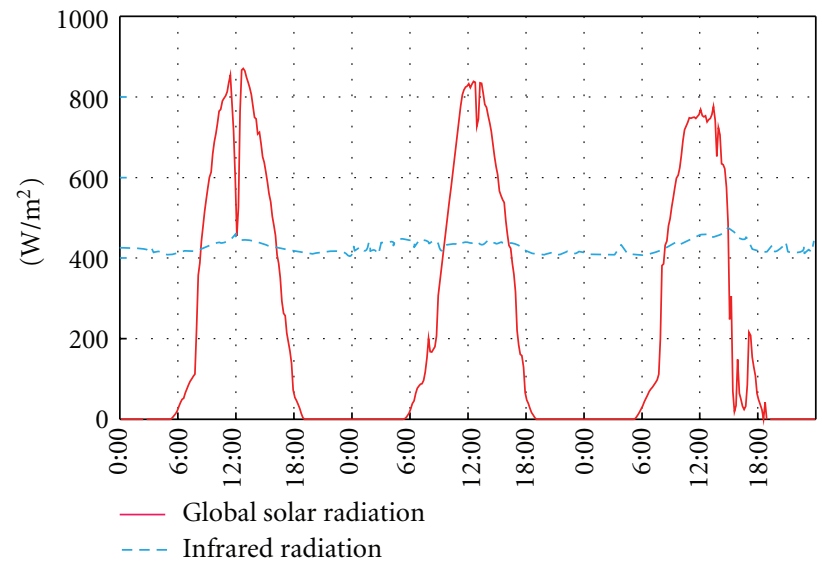

(a) Global solar radiation and infrared radiation near the observation site

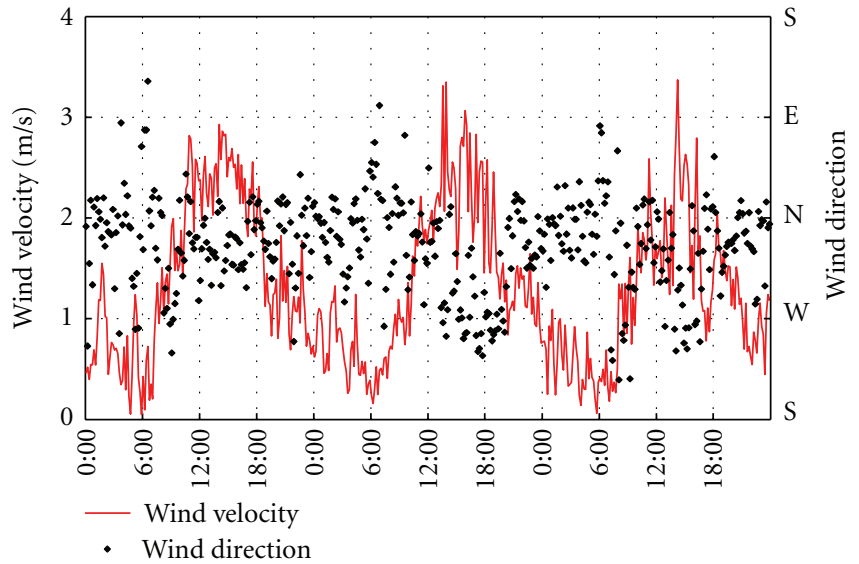

(b) Wind direction and velocity at a height of $2.0 \mathrm{~m}$ near the observation site

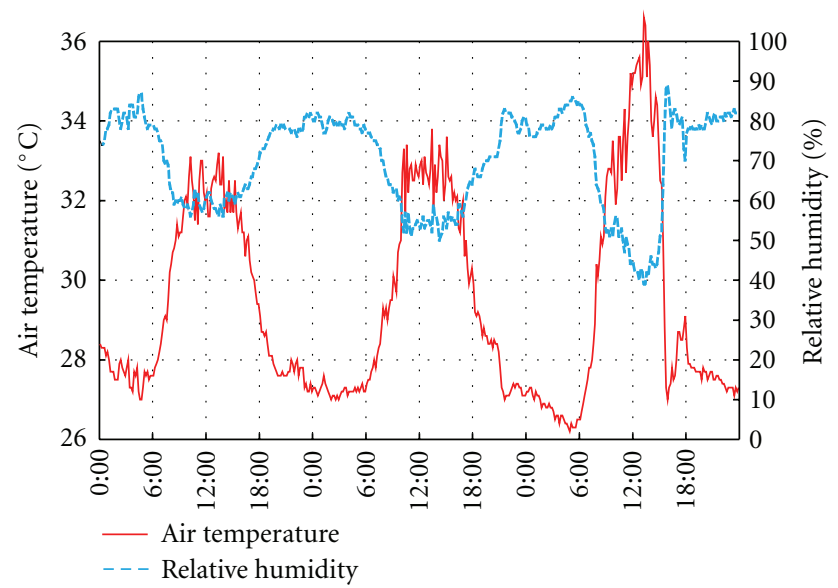

(c) Air temperature and relative humidity at a height of $1.5 \mathrm{~m}$ near the observation site

Figure 4: Weather conditions on August 3 to 5, 2005.

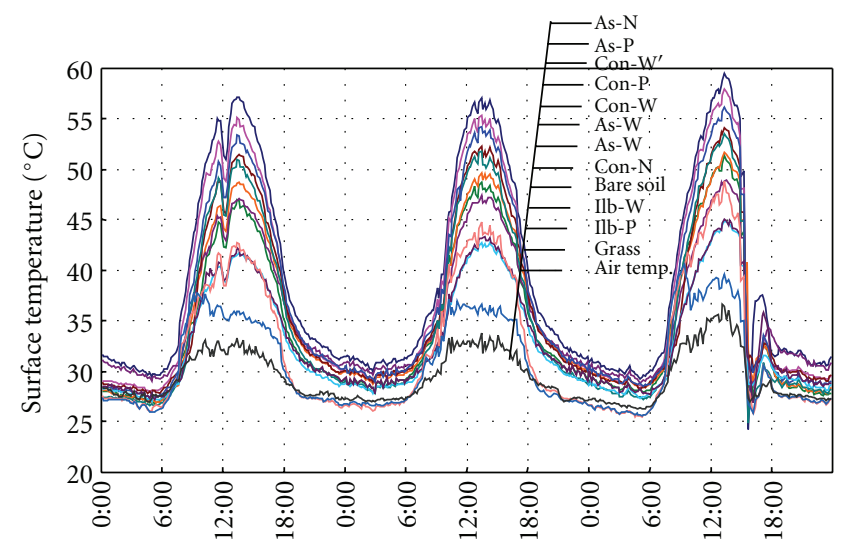

Figure 5: Observed values of surface temperature for each pavement surface on August 3 to 5, 2005.

3.2. Solar Reflectance. The net radiation meter, which records the downward and upward short-wave radiation and the downward and upward long-wave radiation, is set at a height of $30 \mathrm{~cm}$ above the center of each target surface. The shape factor between the target surface $(2 \mathrm{~m} \times 2 \mathrm{~m})$ and radiation sensor is over $95 \%$.

For each surface, observations are carried out for $10 \mathrm{~min}$ with sampling every 10 s from 10:00 to 14:00 on July 27, 2005, when the solar altitude is high and the downward shortwave radiation is stable. This is a dry surface condition for reflectance. The solar reflectance on each pavement surface is shown in Table 3. The solar reflectance on Con-N is larger than that on the other cement concrete surfaces because the presence of voids increases the dark area on Con-P and Con-W. The solar reflectance on As-W is larger than that on the other asphalt surface because the liquid water-retention agent injected into the voids of As-W is white. The solar reflectance on the interlocking blocks is relatively large because the material has a bright color.

3.3. Latent Heat Flux. Irrigation corresponding to $10 \mathrm{~mm} / \mathrm{h}$ rainfall was carried out from 17:00 to 18:00 on August 2, 2005, the day before the observations. Then, the weights of the cores, boxes, and blocks were recorded every hour in the morning and every two hours in the afternoon on the first day (August 3), every two hours on the second day 
TABLE 3: Solar reflectance on each pavement surface (dry surface condition).

\begin{tabular}{lcccccccccccc}
\hline Pavement & As-N & As-P & As-W & As-W' & Con-N & Con-P & Con-W & Con-W' & Ilb-P & Ilb-W & Soil & Grass \\
\hline Reflectance & 0.082 & 0.074 & 0.172 & 0.267 & 0.294 & 0.141 & 0.202 & 0.150 & 0.397 & 0.394 & 0.225 & 0.210 \\
\hline
\end{tabular}

(August 4), and at 8:00 and 13:00 on the third day (August $5)$. Three cores, boxes, and blocks for each experimental surface were weighed for estimating the evaporative flux. The cores and boxes used for recording the weight are shown in Figures 6 and 7. The core diameter was $15 \mathrm{~cm}$, and the core depth was $5 \mathrm{~cm}$ for the asphalt surface and $15 \mathrm{~cm}$ for the cement concrete surface, as determined by the depth of each surface layer. Blocks $(20 \mathrm{~cm} \times 10 \mathrm{~cm} \times 8 \mathrm{~cm})$ were picked up and weighed. An electronic balance was used for recording the weight. Because it was measured in the field, moisture content in the material was not measured.

The estimated values of evaporative flux obtained from the observed weights for August 3 to 5, 2005, are shown in Figure 8. Because it rained at around 15:00 on August 5, the observation period was considered to be over at that time. On the first day after the irrigation, a difference in the amount of evaporative flux for each pavement surface was confirmed, but on the second day, the evaporative flux was quite small for all the pavement surfaces, except for grass and bare soil. We conducted the same experiments three times in August 2005 and 2004. The estimation results of the latent heat flux were quite similar for each experiment.

\section{Analysis of Surface Heat Budget}

4.1. Surface Heat Budget Equation. The surface heat budget is represented as follows, by assuming that evaporation occurs at the surface:

$$
\begin{gathered}
R_{n}=A+V+l E \\
A=-\left.\lambda \frac{\partial T}{\partial z}\right|_{z=0}, \\
V=\alpha\left(T_{s}-T_{a}\right), \\
l E=l \cdot \beta \cdot \alpha_{w}\left(X_{s}-X_{a}\right)=\frac{l \cdot \beta \cdot \alpha\left(X_{s}-X_{a}\right)}{C_{p}},
\end{gathered}
$$

where $R_{n}$ is the net radiation $\left(\mathrm{W} / \mathrm{m}^{2}\right), A$ the conduction heat flux $\left(\mathrm{W} / \mathrm{m}^{2}\right), V$ the sensible heat flux $\left(\mathrm{W} / \mathrm{m}^{2}\right), l E$ the latent heat flux $\left(\mathrm{W} / \mathrm{m}^{2}\right), \lambda$ the heat conductivity $(\mathrm{W} /(\mathrm{mK})), \alpha$ the sensible heat transfer coefficient $\left(\mathrm{W} /\left(\mathrm{m}^{2} \mathrm{~K}\right)\right), T_{s}$ the surface temperature $\left({ }^{\circ} \mathrm{C}\right), T_{a}$ the air temperature $\left({ }^{\circ} \mathrm{C}\right), l$ the latent heat of water $(\mathrm{J} / \mathrm{kg}), \beta$ the evaporative efficiency $(-), \alpha_{w}$ the evaporative transfer coefficient $\left(\mathrm{kg} /\left(\mathrm{m}^{2} \mathrm{~h}\left(\mathrm{~kg} / \mathrm{kg}^{\prime}\right)\right)\right), C_{p}$ the specific heat $(\mathrm{J} /(\mathrm{kgK})), X_{s}$ the saturated absolute humidity of the surface $\left(\mathrm{kg} / \mathrm{kg}^{\prime}\right)$, and $X_{a}$ the absolute humidity of air $\left(\mathrm{kg} / \mathrm{kg}^{\prime}\right)$.

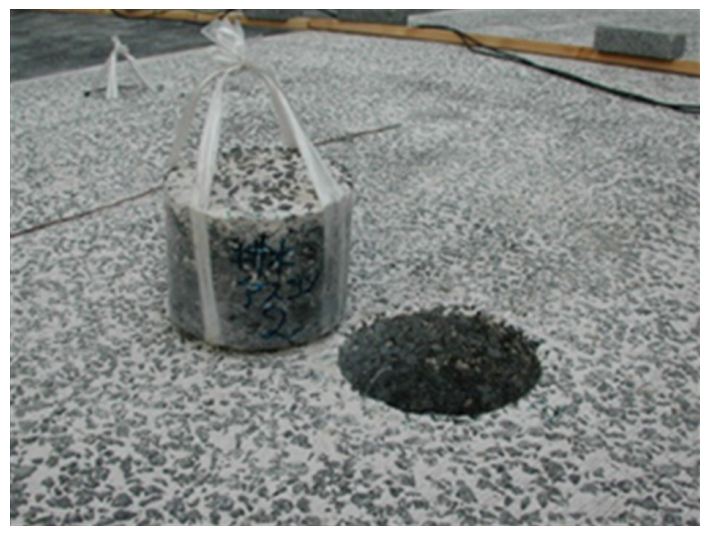

FIGURE 6: Core for recording the weight ( $15 \mathrm{~cm}$ diameter).

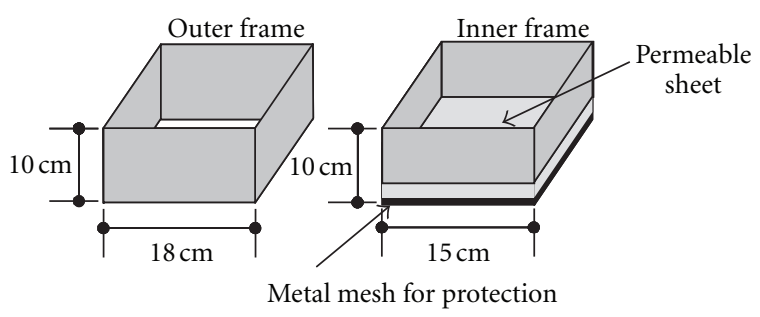

FIGURE 7: Box for recording the weight of grass and bare soil.

4.2. Estimation of Heat Conductivity and Heat Capacity. The temperature profile in the material is calculated by the following one-dimensional unsteady heat conduction equation:

$$
\left.\frac{\partial T}{\partial t}\right|_{m}=\frac{\lambda}{c} \frac{\partial T^{2}}{\partial z^{2}}
$$

where $c$ is the heat capacity $\left(\mathrm{J} /\left(\mathrm{m}^{3} \mathrm{~K}\right)\right)$.

In this study, $\lambda$ and $c$ are estimated on the basis of the observed heat flux and temperature data in each pavement. The differential equations for (2) and (5) are expressed as follows:

$$
\begin{aligned}
& A=-\lambda \frac{\Delta T}{\Delta z}=\frac{\lambda}{\Delta z}\left(T_{s}-T_{1}\right), \\
& \lambda \frac{1}{\left(\Delta z_{1} / 2\right)+\left(\Delta z_{2} / 2\right)}\left(\frac{T_{m-1}-T_{m}}{\Delta z_{1}}-\frac{T_{m}-T_{m+1}}{\Delta z_{2}}\right) \\
& \quad=c \frac{\left(T_{m}-T_{m}^{*}\right)}{\Delta t},
\end{aligned}
$$

where $\Delta z$ is the distance between $T_{s}$ and $T_{1}(\mathrm{~m}), \Delta z_{1}$ the distance between $T_{m-1}$ and $T_{m}(\mathrm{~m})$, and $\Delta z_{2}$ the distance between $T_{m}$ and $T_{m+1}(\mathrm{~m})$. When the observed values are substituted in (6), a relationship graph for estimating $\lambda$ is obtained, as shown in Figure 9. The slope of the linear approximation is interpreted as $\lambda$. Then, when the estimated 


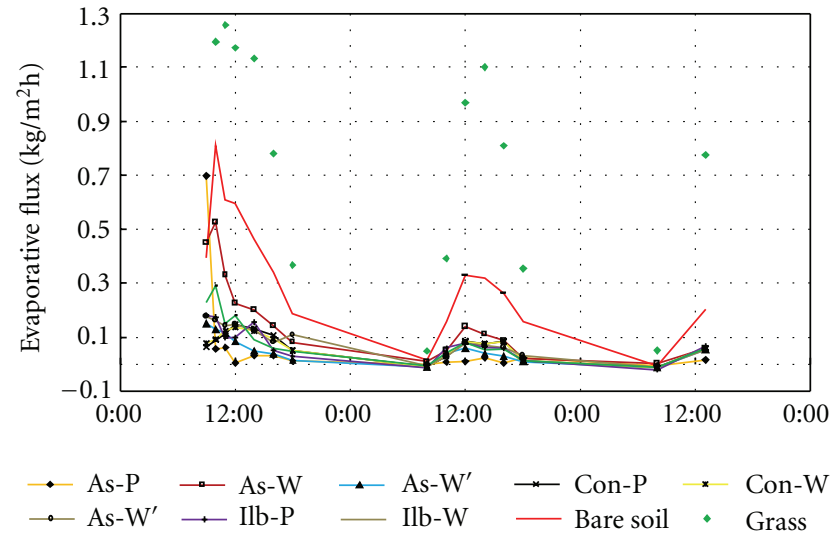

FIGURE 8: Values of evaporative flux estimated from the observed weights on August 3 to 5, 2005.

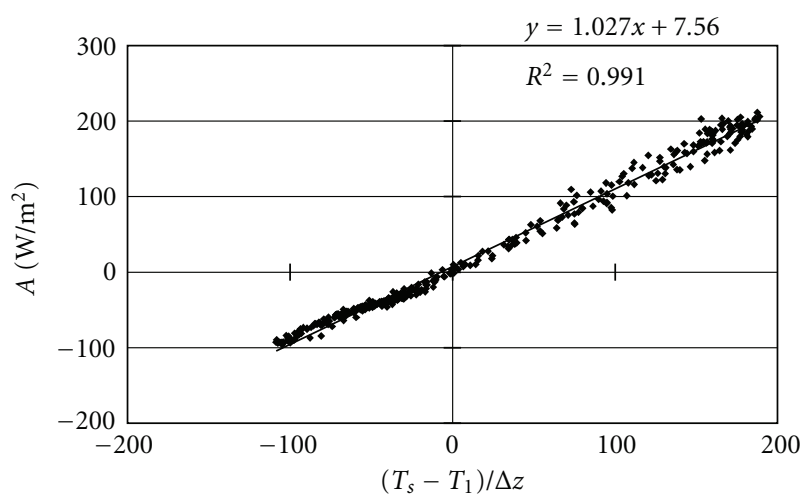

FIGURE 9: Relationship graph for estimation of heat conductivity in the case of As-N.

$\lambda$ and the observed values are substituted in (7), a relationship graph for estimating $c$ is obtained, as shown in Figure 10. The slope of the linear approximation is interpreted as $c$. The estimated values of $\lambda$ and $c$ for each pavement surface are shown in Table 4. Only those values near the surface are estimated.

4.3. Estimation of Evaporative Efficiency. The evaporation efficiency $\beta$ is required for determining the latent heat flux from (4). The following equation is obtained by integrating and transforming (1), (3), and (4):

$$
R_{n}-A=\alpha\left\{\left(T_{s}-T_{a}\right)+l \cdot \beta \cdot \frac{1}{C_{p}}\left(X_{s}-X_{a}\right)\right\}
$$

Since $R_{n}, A, T_{s}, T_{a}$, and $X_{a}$ are obtained by observation, the only unknowns are $\alpha$ and $\beta$. The following two cases for determining $\alpha$ and $\beta$ are assumed.

(1) Using the Jurges Formula [21] to Determine the Sensible Heat Transfer Coefficient $\alpha$. By comparing the daily integrated latent heat flux obtained from the observed weight of cores with that from (4), the daily averaged $\beta$ is estimated. In this study, $\beta$ is assumed to be constant over one day

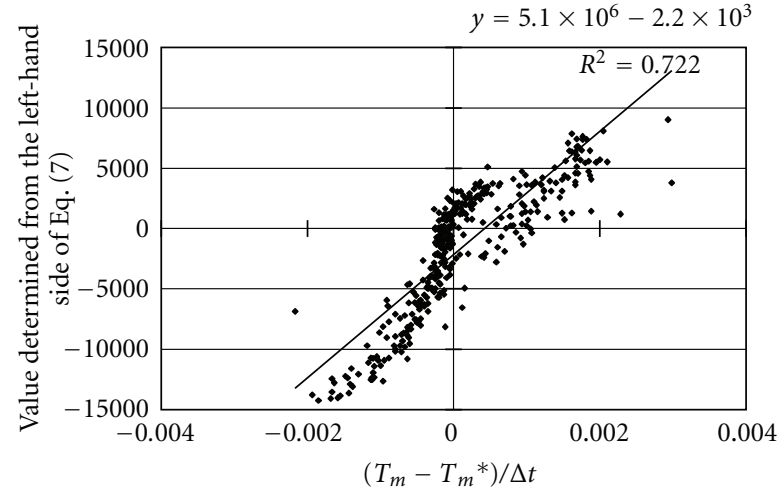

FIGURE 10: Relationship graph for estimation of heat capacity in the case of As-N.

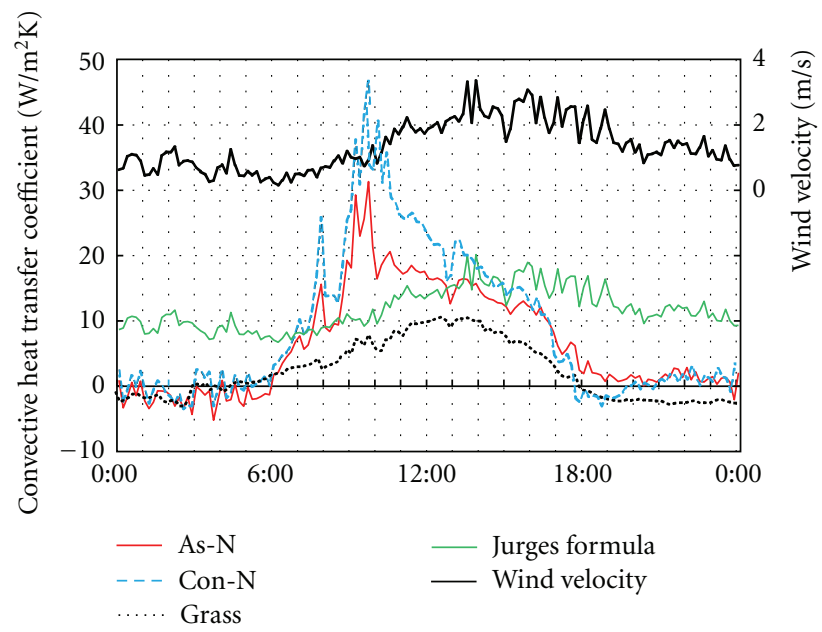

FIGURE 11: Estimated values of sensible heat transfer coefficient on August 4, 2005.

because the moisture condition in the material may not change significantly in one day. The values of $\beta$ estimated using the $\alpha$ value calculated by the Jurges formula are shown in Table 5.

(2) Using (8) to Determine $\alpha$. In (8), if $\beta$ is known, $\alpha$ is obtained by comparing the daily integrated latent heat flux obtained from the observed core weights with that from (4). The values of $\beta$ estimated using the $\alpha$ value calculated from (8) are shown in Table 6.

The values of $\alpha$ determined by methods (1) and (2) are shown in Figure 11. The values for As-N, Con-N, and grass are shown as representative values. The diurnal variation is similar for the other surfaces. The $\alpha$ value estimated from method (1) has a peak in the afternoon, while that estimated from method (2) has a peak in the morning. This difference is considered to be influenced by the residues of the surface heat budget, because the estimated conduction heat flux in the morning is relatively small owing to the lower surface temperature recorded by the thermometer. Therefore, the surface temperature should be treated more carefully. 
TABLE 4: Estimated values of heat conductivity $(\mathrm{W} /(\mathrm{mK}))$ and heat capacity $\left(\mathrm{MJ} /\left(\mathrm{Km}^{3}\right)\right)$ for each pavement surface.

\begin{tabular}{lcccccccccccc}
\hline Pavement & As-N & As-P & As-W & As-W & Con-N & Con-P & Con-W & Con-W & Ilb-P & Ilb-W & Soil & Grass \\
\hline Conductivity & 1.03 & 0.90 & 1.03 & 1.43 & 2.21 & 1.21 & 1.19 & 0.90 & 1.47 & 1.16 & 0.74 & 0.72 \\
Capacity & 5.1 & 0.9 & 6.3 & 0.9 & 7.2 & 1.0 & 1.5 & 1.2 & 2.9 & 1.6 & 10.0 & 8.1 \\
\hline
\end{tabular}

TABLE 5: Values of evaporative efficiency estimated using the sensible heat transfer coefficient calculated by the Jurges formula.

\begin{tabular}{lcccccccccc}
\hline Pavement & As-P & As-W & As-W' & Con-P & Con-W & Con-W & Ilb-P & Ilb-W & Soil & Grass \\
\hline 1st day (Aug. 3) & 0.01 & 0.11 & 0.03 & 0.04 & 0.04 & 0.04 & 0.07 & 0.08 & 0.31 & 0.93 \\
2nd day (Aug. 4) & 0.01 & 0.04 & 0.02 & 0.02 & 0.03 & 0.02 & 0.04 & 0.04 & 0.16 & 0.79 \\
3rd day (Aug. 5) & 0.01 & 0.03 & 0.03 & 0.03 & 0.03 & 0.02 & 0.05 & 0.05 & 0.03 & 0.69 \\
\hline
\end{tabular}

TABLE 6: Values of evaporative efficiency estimated using the sensible heat transfer coefficient calculated by (8).

\begin{tabular}{lcccccccccc}
\hline Pavement & As-P & As-W & As-W' & Con-P & Con-W & Con-W' & Ilb-P & Ilb-W & Soil & Grass \\
\hline 1st day (Aug. 3) & 0.01 & 0.09 & 0.06 & 0.04 & 0.04 & 0.05 & 0.05 & 0.07 & 1.00 & 1.00 \\
2nd day (Aug. 4) & 0.00 & 0.03 & 0.03 & 0.02 & 0.02 & 0.02 & 0.03 & 0.02 & 0.20 & 1.00 \\
3rd day (Aug. 5) & 0.00 & 0.02 & 0.03 & 0.01 & 0.02 & 0.01 & 0.03 & 0.02 & 0.09 & 1.00 \\
\hline
\end{tabular}

TABLE 7: Values of evaporative efficiency estimated using the sensible heat transfer coefficient calculated by (9).

\begin{tabular}{lcccccccccc}
\hline Pavement & As-P & As-W & As-W' & Con-P & Con-W & Con-W' & Ilb-P & Ilb-W & Soil & Grass \\
\hline 1st day (Aug. 3) & 0.009 & 0.115 & 0.030 & 0.044 & 0.044 & 0.051 & 0.079 & 0.095 & 0.456 & 0.508 \\
2nd day (Aug. 4) & 0.005 & 0.040 & 0.018 & 0.026 & 0.027 & 0.023 & 0.046 & 0.040 & 0.204 & 0.513 \\
3rd day (Aug. 5) & 0.005 & 0.031 & 0.029 & 0.027 & 0.030 & 0.024 & 0.068 & 0.058 & 0.122 & 0.502 \\
\hline
\end{tabular}

\section{Calculation of Surface Heat Budget}

5.1. Calculation Method. The following equation [3] is obtained by integrating and transforming (1), (3), and (6):

$$
T_{s}=\frac{R_{n}-l E+\alpha \cdot T_{a}+(\lambda / \Delta z) \cdot T_{1}}{\alpha+(\lambda / \Delta z)} .
$$

Since $T_{s}$ is required for calculating $R_{n}$ and $l E$, it is calculated using the convergence method. By comparing the daily integrated latent heat flux obtained from the observed core weights, the daily averaged $\beta$ is estimated using the Jurges formula for $\alpha$. The values of $\beta$ estimated using the $\alpha$ value calculated by (9) are shown in Table 7.

5.2. Calculation Results. The estimated values of the surface heat budget for each pavement surface on August 3 to 5, 2005, are shown in Figure 12. The calculated and observed values for several pavement surfaces on August 3 to 5, 2005, are shown in Figure 13, and these values are approximately consistent.

The estimated values of the sensible heat flux from each pavement surface on August 3 to 5, 2005, are shown in Table 8 . The maximum and mean values are also listed. At the maximum value, the reduction in the heat flux from that on As- $\mathrm{N}$ is about $180 \mathrm{~W} / \mathrm{m}^{2}$ for Con-N and about $270 \mathrm{~W} / \mathrm{m}^{2}$ for Ilb-P and Ilb-W. The heat flux reduction is considered to be influenced by albedo for Con- $\mathrm{N}$ and by both albedo and evaporation for Ilb-P and Ilb-W. The reduction in the heat flux from that on As- $\mathrm{N}$ is small for
As-P and As-W because of the small differences in albedo and evaporation. The reduction values for Con-P and Con$\mathrm{W}$ are also small because of the small albedo, despite some evaporation. The reduction on bare soil and grass is large owing to evaporation.

\section{Conclusions}

In this study, the thermal characteristics of pavements for urban heat island mitigation are examined on the basis of observations and analysis of the surface heat budget. The surface heat budget for different surfaces under the same weather conditions is examined, and the sensible heat flux from each target surface is calculated. The parameters affecting the surface heat budget, for example, solar reflectance (albedo), evaporative efficiency, heat conductivity, and heat capacity, are examined.

The following points are discussed on the basis of the results of the surface heat budget analysis for each pavement.

(i) Sensible heat flux is greatly reduced by evaporation on bare soil and grass surfaces. The reduction in the sensible heat flux compared with that on a normal asphalt surface in the daytime and nighttime is about 270 and $40 \mathrm{~W} / \mathrm{m}^{2}$ on bare soil and about 350 and $60 \mathrm{~W} / \mathrm{m}^{2}$ on grass.

(ii) The reduction in the sensible heat flux by interlocking blocks compared with that on a normal asphalt 


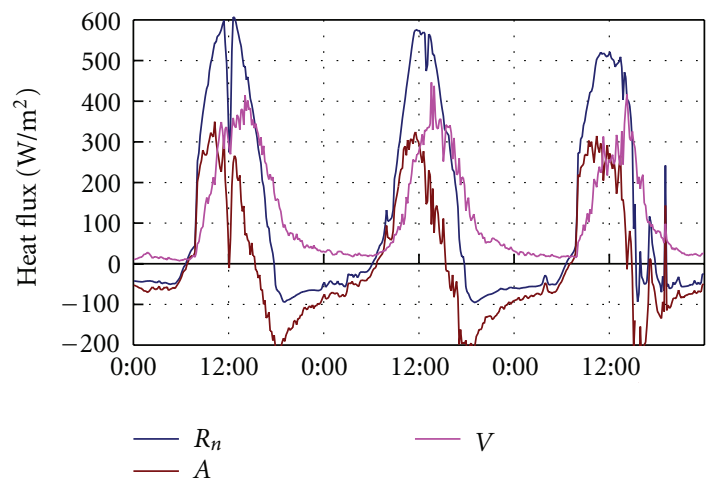

(a) As- $\mathrm{N}$

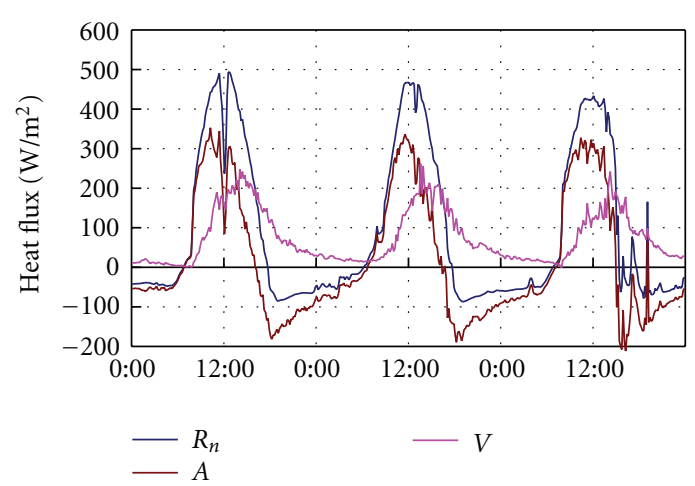

(c) Con-N

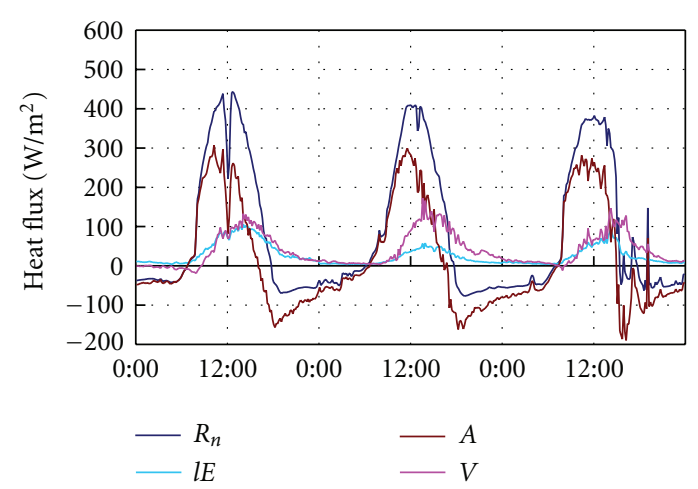

(e) Ilb-W

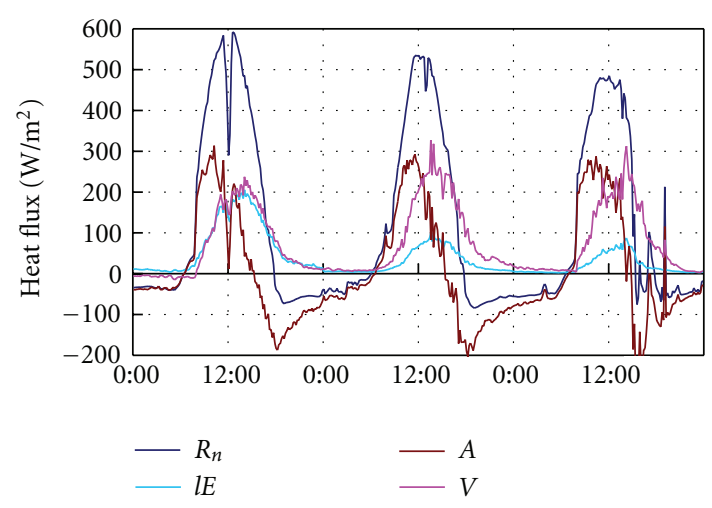

(b) As-W

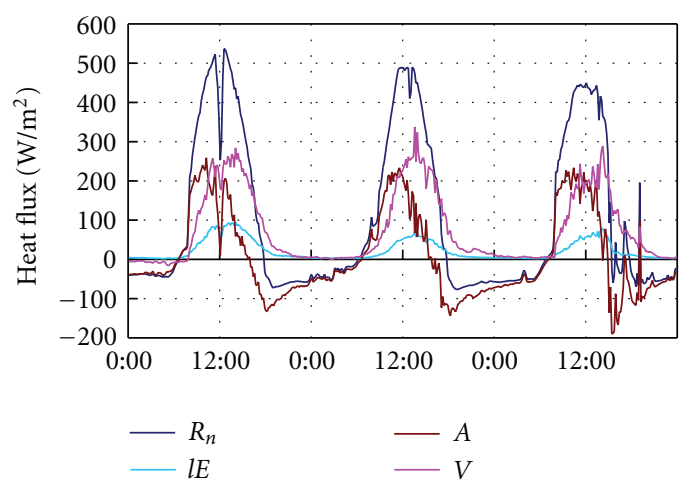

(d) Con-W

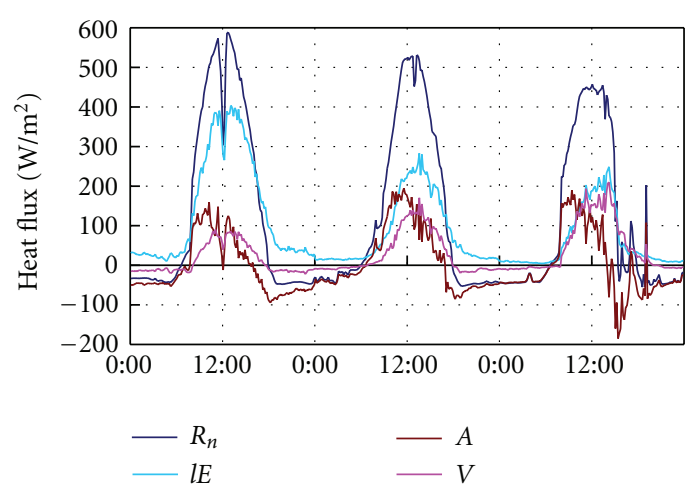

(f) Bare soil

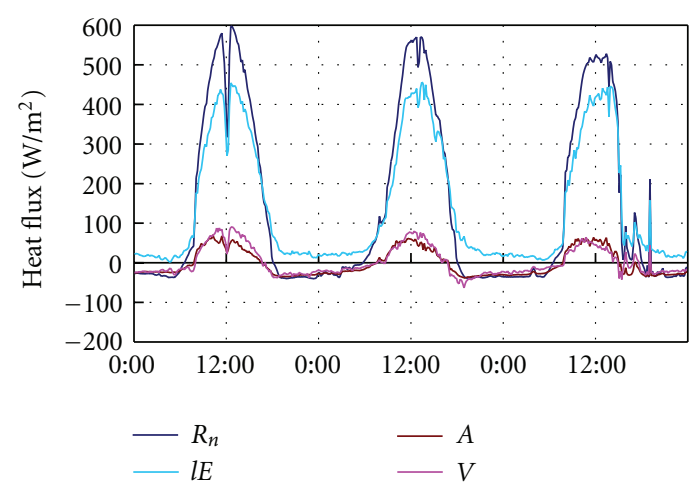

(g) Grass

FIGURE 12: Values of surface heat budget estimated for each pavement surface on August 3 to 5, 2005. 


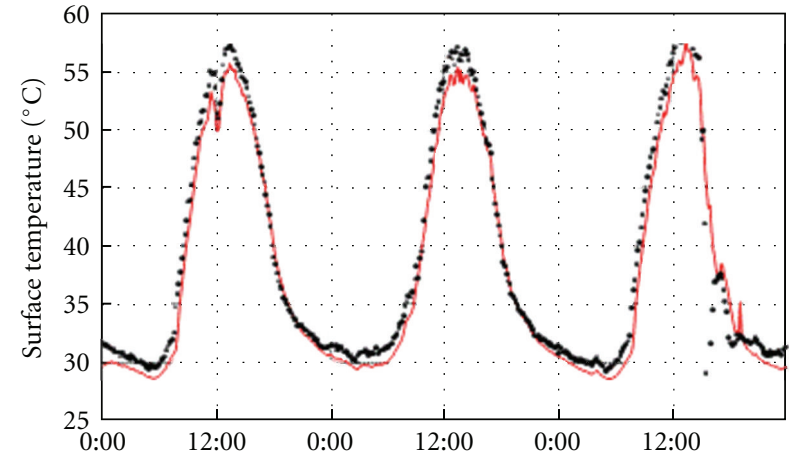

(a) As-N

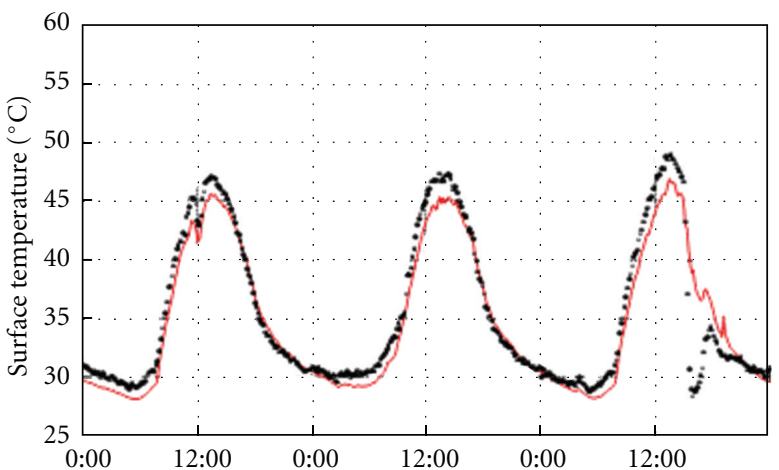

(c) Con-N

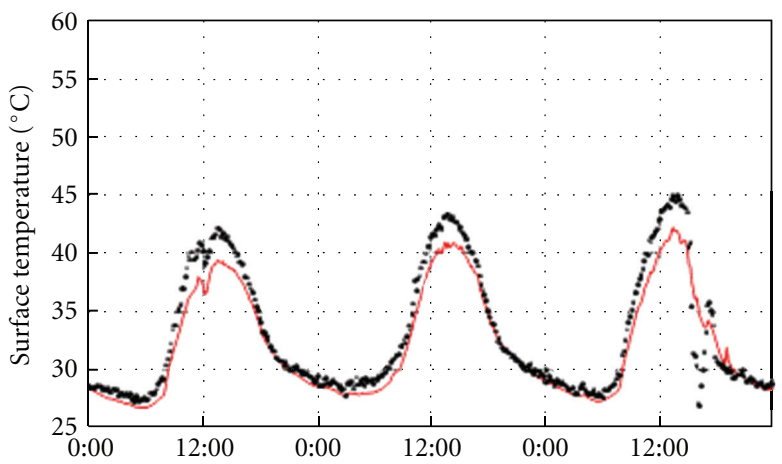

- Calculation

- Observation

(e) Ilb-W

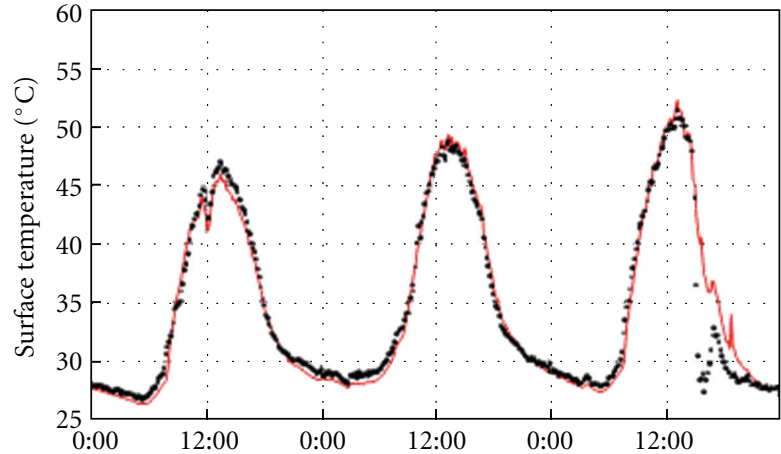

(b) As-W

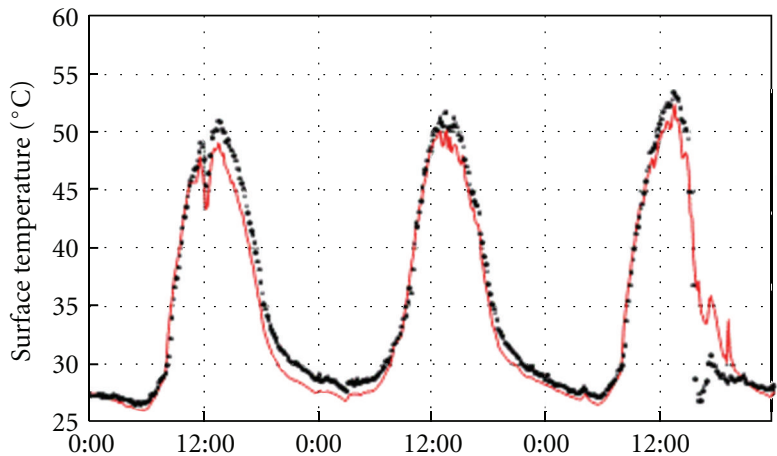

(d) Con-W

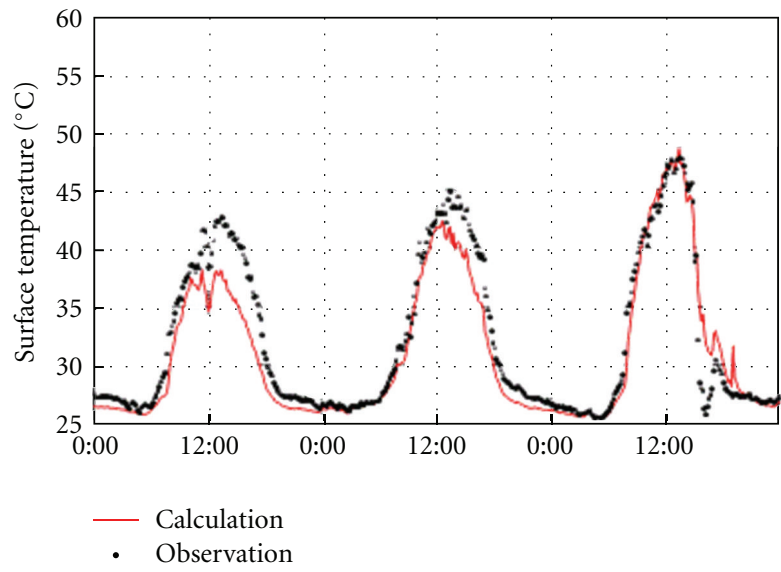

(f) Bare soil

Figure 13: Calculated and observed values of surface temperature for several pavement surfaces on August 3 to 5, 2005.

TABLE 8: Values of sensible heat flux $\left(\mathrm{W} / \mathrm{m}^{2}\right)$ estimated for each pavement surface on August 3 to 5, 2005.

\begin{tabular}{lcccccccccccc}
\hline Pavement & As-N & As-P & As-W & As-W' & Con-N & Con-P & Con-W & Con-W & Ilb-P & Ilb-W & Soil & Grass \\
\hline Maximum & 446.4 & 465.3 & 327.3 & 313.7 & 262.4 & 358.1 & 337.1 & 365.9 & 163.9 & 172.6 & 169.9 & 90.9 \\
Mean & 128.1 & 117.9 & 75.3 & 72.6 & 79.9 & 84.2 & 79.0 & 85.6 & 39.9 & 41.3 & 20.0 & 2.9 \\
\hline
\end{tabular}

surface is relatively large, about 280 and $20 \mathrm{~W} / \mathrm{m}^{2}$ in the daytime and nighttime, respectively.

(iii) The reduction in the sensible heat flux for a normal cement concrete surface as compared to that on a normal asphalt surface is about $180 \mathrm{~W} / \mathrm{m}^{2}$ in the daytime, because of a slightly higher albedo.
However, the reduction in the nighttime is small owing to a slightly larger thermal mass.

(iv) The reduction in the sensible heat flux by porous and water-retaining concrete surfaces compared with that on a normal asphalt surface is about $100 \mathrm{~W} / \mathrm{m}^{2}$ in the daytime, which is lower than that for the normal 
cement concrete surface, because the albedo of these surfaces is a little lower than that of the normal cement concrete surface. However, the sensible heat flux reduction in the nighttime is about $20 \mathrm{~W} / \mathrm{m}^{2}$ because of a slightly smaller thermal mass.

(v) The reduction in the sensible heat flux by a waterretaining asphalt surface as compared with that on a normal asphalt surface is about $140 \mathrm{~W} / \mathrm{m}^{2}$ in the daytime, owing to evaporation and albedo. However, the heat flux reduction by a porous asphalt surface is almost 0 , because there is no evaporation.

The pavements targeted in this study do not represent all the pavements used for mitigating the urban heat island effect. However, the heat budget for each surface shown in this paper is generally representative of that for several kinds of pavements used for urban heat island mitigation. The results of this study may act as a guide for the future development of pavement materials.

\section{Acknowledgments}

The authors wish to thank Dr. M. Nishioka and M. Nabeshima of Osaka City University and Mr. Y. Ando, K. Yasuhisa, and H. Ohishi of Sumitomo Osaka Cement Co., Ltd. for their cooperation and for assisting them in the setup of observation sites.

\section{References}

[1] H. Akbari, S. Konopacki, and M. Pomerantz, "Cooling energy savings potential of reflective roofs for residential and commercial buildings in the United States," Energy, vol. 24, no. 5, pp. 391-407, 1999.

[2] A. Teemusk and Ü. Mander, "Greenroof potential to reduce temperature fluctuations of a roof membrane: a case study from Estonia," Building and Environment, vol. 44, no. 3, pp. 643-650, 2009.

[3] H. Takebayashi and M. Moriyama, "Surface heat budget on green roof and high reflection roof for mitigation of urban heat island," Building and Environment, vol. 42, no. 8, pp. 2971-2979, 2007.

[4] N. H. Wong, Y. Chen, C. L. Ong, and A. Sia, "Investigation of thermal benefits of rooftop garden in the tropical environment," Building and Environment, vol. 38, no. 2, pp. 261-270, 2003.

[5] S. Onmura, M. Matsumoto, and S. Hokoi, "Study on evaporative cooling effect of roof lawn gardens," Energy and Buildings, vol. 33, no. 7, pp. 653-666, 2001.

[6] E. Eumorfopoulou and D. Aravantinos, "The contribution of a planted roof to the thermal protection of buildings in Greece," Energy and Buildings, vol. 27, no. 1, pp. 29-36, 1998.

[7] A. Hoyano, "Climatological uses of plants for solar control and the effects on the thermal environment of a building," Energy and Buildings, vol. 11, no. 1-3, pp. 181-199, 1988.

[8] Y. Chen and N. H. Wong, "Thermal benefits of city parks," Energy and Buildings, vol. 38, no. 2, pp. 105-120, 2006.

[9] T. V. Ca, T. Asaeda, and E. M. Abu, "Reductions in air conditioning energy caused by a nearby park," Energy and Buildings, vol. 29, no. 1, pp. 83-92, 1998.
[10] T. Honjo and T. Takakura, "Simulation of thermal effects of urban green areas on their surrounding areas," Energy and Buildings, vol. 15, no. 3-4, pp. 443-446, 1990.

[11] I. Saito, O. Ishihara, and T. Katayama, "Study of the effect of green areas on the thermal environment in an urban area," Energy and Buildings, vol. 15, no. 3-4, pp. 493-498, 1990.

[12] S. Kawashima, "Effect of vegetation on surface temperature in urban and suburban areas in winter," Energy and Buildings, vol. 15, no. 3-4, pp. 465-469, 1990.

[13] R. Avissar, "Potential effects of vegetation on the urban thermal environment," Atmospheric Environment, vol. 30, no. 3, pp. 437-448, 1996.

[14] H. Taha, S. Konopacki, and S. Gabersek, "Impacts of largescale surface modifications on meteorological conditions and energy use: a 10-region modeling study," Theoretical and Applied Climatology, vol. 62, no. 3-4, pp. 175-185, 1999.

[15] E. Alexandri and P. Jones, "Temperature decreases in an urban canyon due to green walls and green roofs in diverse climates," Building and Environment, vol. 43, no. 4, pp. 480-493, 2008.

[16] T. Ozaki and Y. Suzuki, "Study on the contribution of waterretentive ceramic tile to the reduction of environment heat accumulation," Journal of Hydraulic, Coastal and Environmental Engineering, vol. 42, pp. 61-66, 1998.

[17] T. Ozaki, Y. Suzuki, K. Hadano et al., "A field test on the contribution of water-retentive ceramic tile to the reduction of environment heat accumulation," Journal of Hydraulic, Coastal and Environmental Engineering, vol. 43, pp. 239-244, 1999.

[18] M. Nabeshima, M. Nishioka, N. Miki, and S. Tsugou, "Thermal examination of permeable pavement materials, Part 1 Indoor measurement, Part 2 Field measurement, Summaries of Technical Papers of Annual Meeting," AIJ, vol. D-2, pp. 563566, 2002.

[19] H. Akagawa and H. Komiya, "Experimental study on pavement system with continuous wet surface," Journal of Architecture, Planning and Environmental Engineering, no. 530, pp. 79-85, 2000.

[20] K. Narita, I. Misaka, T. Kunishima, Y. Nakayama, and S. Wakabayashi, "Evaluation of water retentive pavement using evaporation efficiency," AIJ Journal of Technology and Design, vol. 20, pp. 187-190, 2004.

[21] A. Hagishima, J. Tanimoto, and K. I. Narita, "Intercomparisons of experimental convective heat transfer coefficients and mass transfer coefficients of urban surfaces," Boundary-Layer Meteorology, vol. 117, no. 3, pp. 551-576, 2005. 

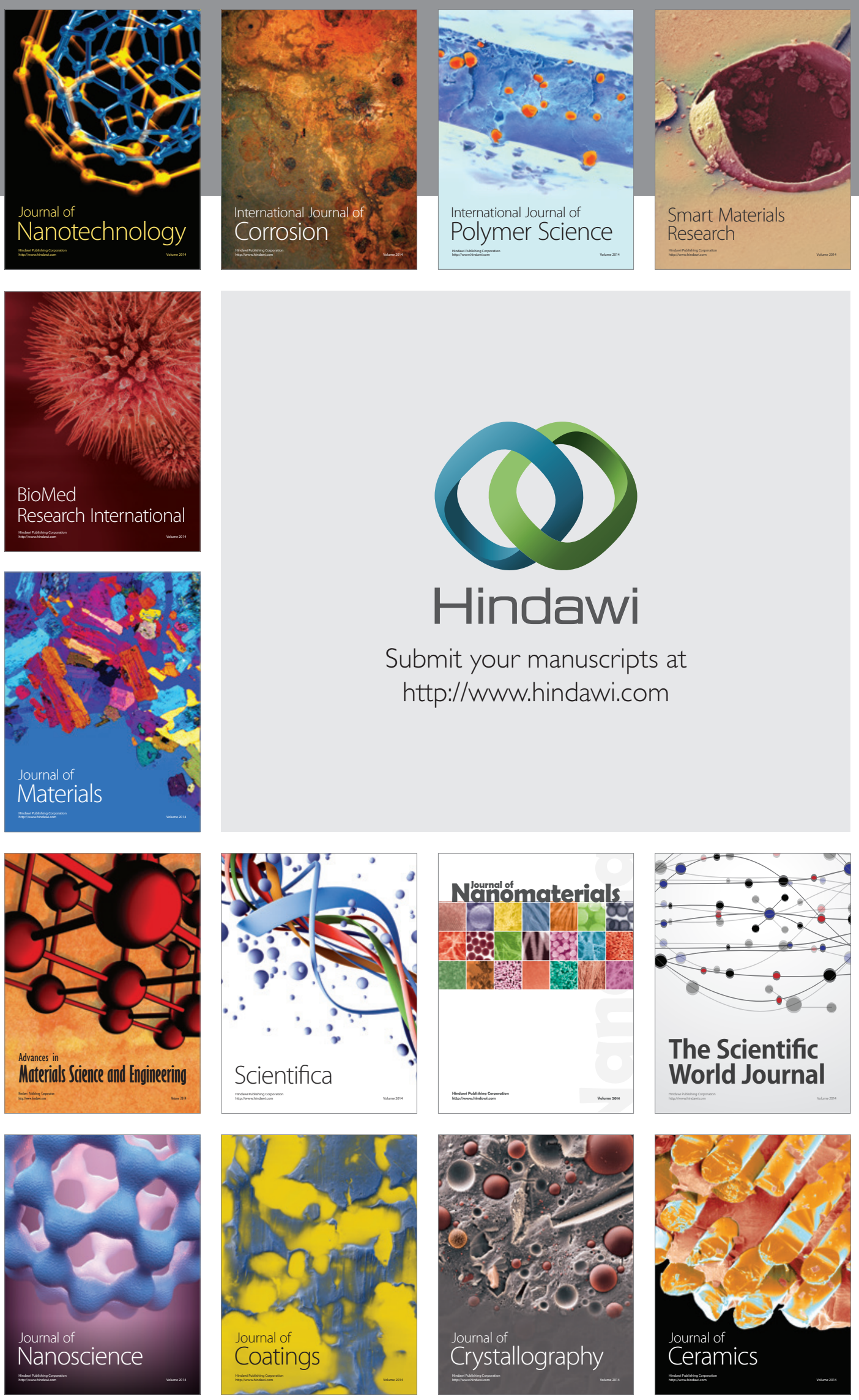

The Scientific World Journal

Submit your manuscripts at

http://www.hindawi.com

\section{World Journal}

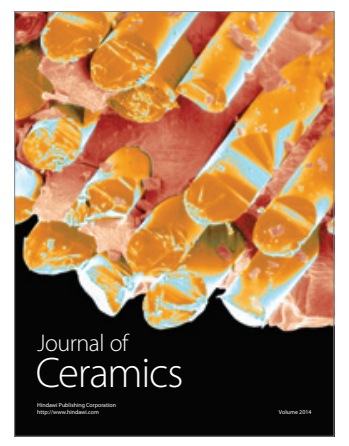

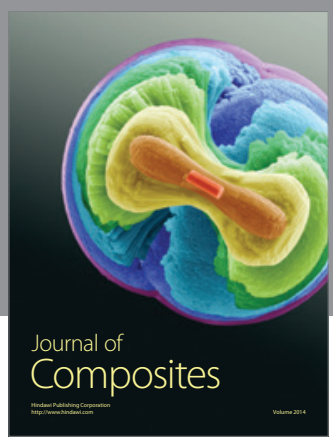
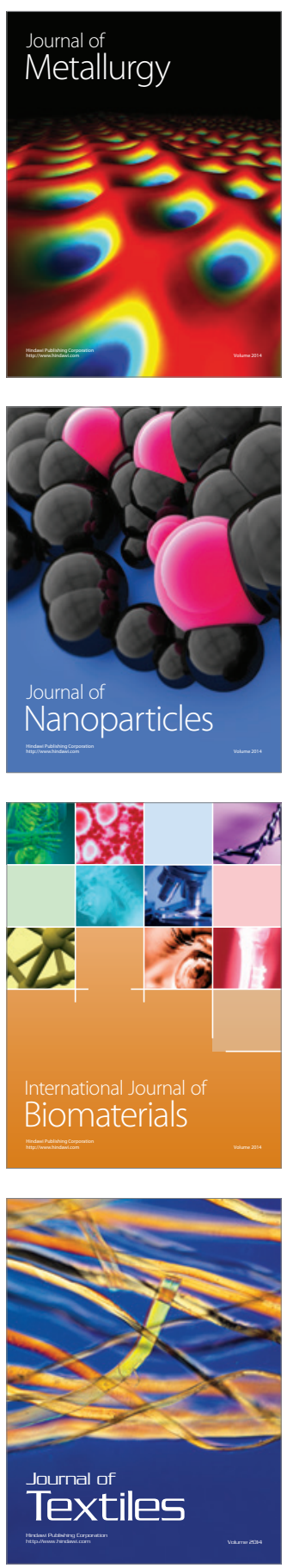